\title{
Nya massor? Motståndets sociala grundvalar
}

\section{Göran Therborn}

SAMMANDRAG: Vilka är de sociala krafter som skulle kunna utmana kapitalets makt under de kommande årtiondena? I denna uppföljande artikel till sin imponerande översikt över vårt unga sekels nya globala klasslandskap, "Klass i det tjugoförsta århundradet" (även den publicerad i detta nummer av Arkiv), analyserar Göran Therborn de möjliga källorna till antikapitalistisk kritik och mobilisering i det dynamiska syd och det gamla nord. Förkapitalistiska befolkningar, "överflödiga" massor, exploaterade arbetare samt ny och gammal medelklass är alla grupper som diskuteras. Slutligen tar sig Therborn även an de rörelser som kan komma att organisera sig utifrån dessa sociala baser. Vilka krav kommer de att föra fram och hur ska de kunna bygga de allianser som kommer vara nödvändiga för att ha möjligheter att påverka den globala utvecklingen i riktning mot ökad jämlikhet och demokrati?

NYCKELORD: samhällskritik; sociala krafter; arbetarrörelse; sociala rörelser; massor; antikapitalism; jämlikhet; syd; nord.

PUbLICERINGSHISTORIK: Översättning av artikeln "New Masses? Social Bases of Resistance" i New Left Review, nr 85 (20I4).

GÖRAN THERBORN är professor emeritus i sociologi vid University of Cambridge och affilierad professor vid Linnéuniversitetet.

E-POSTADRESS: gt274@cam.ac.uk

FÖRSLAG PÅ KÄLLANGIVELSE:

Therborn, Göran (20I4) "Nya massor? Motståndets sociala grundvalar", i Arkiv. Tidskrift för sambällsanalys, $\mathrm{nr} 3$, s. 99-IIO. DOI: http://dx.doi.org/I0.13068/2000-6217.3.4

(C) original: Göran Therborn/New Left Review 2014

(C) svensk version: Göran Therborn/Arkiv förlag \& tidskrift 2014

(publicerad 22 december 20I4)

Artikeln distribueras enligt en upphovsrättslicens från Creative Commons:

Erkännande-Ickekommersiell-IngaBearbetningar 3.o Unported, som medger fri ickekommersiell användning och spridning i oförändrat skick så länge källan anges. 
Arkiv. Tidskrift för samhällsanalys är en sakkunniggranskad vetenskaplig tidskrift för samhällsvetenskap och historia. Samtliga artiklar publiceras fritt tillgängliga på:

www.tidskriftenarkiv.se

(beständig länk, DoI: http://dx.doi.org/IO.I3068/2000-62I7)

Den här artikeln finns tillgänglig i följande format:

PDF \& HTML: via beständig länk, DOI: http://dx.doi.org/IO.I3068/2000-62I7.3.4 EPUB: ingår i e-boksutgåva av numret, ISBN: 978 9I 79242657

TRYCK: ingår i bokutgåva av numret, ISBN: 978 9I 79242664

Grafisk utformning och sidnumrering är identisk i pdf och tryck.

Samtliga artiklar i nr 3 (20I4) nås via beständig länk, DOI: http://dx.doi.org/I0.13068/2000-6217.3

Arkiv. Tidskrift för sambällsanalys ISSN: 2000-62I7 (för elektronisk resurs)

ISSN: 2000-6225 (för tryckta nummer)

ges ut av

Stiftelsen Arkiv för främjande och spridning av samhällsvetenskaplig och historisk forskning

genom

Arkiv förlag \& tidskrift

Box 1559

SE-22I OI Lund

ВESÖK: L Gråbrödersg 3 c, ipg

TEL: O46-I3 3920

ARKIV FÖRLAG: arkiv@arkiv.nu·www.arkiv.nu

TIDSKRIFTEN ARKIV: red@tidskriftenarkiv.se · www.tidskriftenarkiv.se

ANSVARIg UTGIVARE \& CHEFREDAKTÖR: Sven Hort

ADMINistrativ RedAKTÖr: David Lindberg

ReDAKTörer: Paavo Bergman, Lisa Kings, Zhanna Kravchenko 


\title{
Nya massor? \\ Motståndets sociala grundvalar
}

\author{
GÖRAN THERBORN
}

För att en kritik av kapitalismen ska få någon politisk mening måste den ha - eller få - en social bas. Från och med ı8oo-talet och under hela I900-talet fördes den mest framträdande kritiken till kategorin "arbetarfrågan”, eftersom den hade sin bas i den framväxande industriella arbetarklassen. Det var inte en viktig fråga bara för de framväxande arbetarorganisationerna och deras ibland även liberala sympatisörer, utan även för den konservativa opinionen; till och med fascisterna, arbetarrörelsens mest våldsamma fiender, utformade sina organisationer med arbetarorganisationerna som förebild. Industriarbetarna behöll sin centrala position fram till 1970-talet. Då hade ännu en social bas för den antikapitalistiska kampen uppstått, i de antikoloniala rörelserna, som mobiliserade sig kring frågan om nationell frigörelse och mot imperialistisk "utveckling" genom fortsatt beroende.

De senaste trettio åren har dock avindustrialiseringen i nord hejdat arbetarnas marsch framåt och vänt den. Här har den "stora dialektiken” - det vill säga sammandrabbningen mellan produktivkrafternas ökande samhälleliga karaktär och det privata ägandet av dem - upphävts. Samtidigt har den framgångsrika industrialiseringen av ledande länder i syd hittills under samma period i stor utsträckning inneburit att kapitalistisk utveckling nu betraktas som möjlig i Asien, Afrika och Latinamerika, i

Ursprungligen publicerad som "New Masses? Social Bases of Resistance" i New Left Review, nr 85 (2014). 
motsats till vad de en gång inflytelserika beroendeteorierna stipulerade. Finns det i dag några framväxande sociala krafter som till sin funktion kan motsvara 1900-talets organiserade arbetarklass och antikoloniala rörelser? Helt klart finns för närvarande inga tydliga breda antikapitalistiska skikt - en ny situation för kapitalismen, om vi tar de senaste I5O åren som utgångspunkt. Tittar vi å andra sidan inte efter antikapitalistiska rörelser utan i stället efter massformationer som kan vara potentiellt kritiska till dagens kapitalistiska utveckling, uppenbarar sig viktiga sociala krafter. Vi kan urskilja fyra sådana krafter.

\section{Från marginalen}

Den första potentiellt kritiska samhällskraften består av förkapitalistiska befolkningsgrupper som gör motstånd mot intrång från storfinansen. Ursprungsbefolkningarna, som på senare tid stärkt sin ställning något, är här viktigast. De är av politisk betydelse framför allt i Anderna i Sydamerika och i Indien, men på större delen av det södra halvklotet är de närvarande, och de har utvecklat internationella nätverk. Både till antal och till resurser är de svaga, förutom på lokal nivå, men kampen kan länkas till viktiga bredare motståndsrörelser. För tillfället är de en kraft att räkna med i Bolivia som huvudpart i en komplicerad regeringskoalition, och i Indien som kärnan i ett omfattande uppror. I båda fallen står de under ledning av organisatörer med rötter i arbetarrörelsen: i Bolivia avskedade gruvarbetare som blivit kokaodlare och i centrala Indien maoistiska yrkesrevolutionärer. På senare tid har de sistnämnda lidit svåra nederlag, men de har varken besegrats eller krossats. I Mexiko kontrollerar zapatisterna fortfarande Lacandonaregionen i Chiapas. Sådan mobilisering kan vara motsägelsefull: när bönder i det kommunistiskt styrda Västbengalen försvarade sin mark mot industriella utvecklingsprojekt hindrade de en vändning liknande den i Kina och förde en högerregim till makten.

Den andra, till största delen utomkapitalistiska, kritiska kraften består av de hundratals miljoner jordlösa bönder, daglönare och gatuförsäljare som utgör merparten av slumbefolkningen i stora delar av Afrika, Asien och Latinamerika. (Deras motsvarighet i nord skulle kunna vara det väx- 
ande antalet marginaliserade ungdomar, både infödda och invandrade, som står utanför arbetsmarknaden.) Potentiellt utgör de en viktig källa till destabilisering av kapitalismen. Den uppdämda ilska och det våld som ryms i dessa befolkningsskikt har ofta, ibland på brutala sätt, visat sig vara explosiva, i etniska pogromer eller bara kravallartad vandalism. Men dessa "jordens fördömda" har också varit indragna i kampen mot vräkningar och för vatten och elektricitet. De spelade en viktig roll under revolterna i arabvärlden 201 och under de regeringsfientliga protesterna mot åtstramningarna längs norra Medelhavskusten och Svartahavskusten: Grekland, Spanien, Bulgarien, Rumänien.

Under vilka förhållanden kan dessa krafter förenas med ett livskraftigt samhällsekonomiskt alternativ? Det är uppenbart att varje sådant kritiskt alternativ skulle behöva tala direkt till deras grundläggande intressen - deras gemensamma existentiella identitet och deras sätt att tjäna sitt levebröd. Ett sådant alternativ skulle behöva utveckla sätt att kommunicera som når djupt ner i dessa befolkningslager och ger upphov till karismatiska ledare med vida nätverk, personliga såväl som elektroniska. Eftersom särskilt städernas befolkning sannolikt inte kommer att organisera sig kommer denna potentiellt kritiska kraft inte att skrida till handling utan en central utlösande händelse, vars karaktär det är omöjligt att förutse.

Det kapitalistiska lönearbetets vardagsdialektik finns naturligtvis fortfarande i allra högsta grad kvar, även om den geografiskt ser annorlunda ut. Den kvarvarande industriarbetarklassen i nord är ännu alltför svag för att utgöra något antikapitalistiskt hot, men åtstramningarna och den kapitalistiska offensiven ger upphov till vissa avgränsade protester, inte minst i Frankrike, där den organiserade arbetarklassen 2010 hotade att störa bensinleveranserna och stålarbetare 2012 ockuperade sina fabriker. De nya arbetarna inom tillverkningsindustrin i Kina, Bangladesh, Indonesien och på andra ställen i syd kan ha större möjligheter att ställa antikapitalistiska krav, men deras ställning försvagas av den enorma tillgången på arbetare, och de håller redan på att bli omsprungna av mer fragmenterade anställningsmönster liknande tjänstesektorns. Upprepade försök att bilda arbetarpartier har gjorts, från Nigeria till Indonesien, men försöken har strandat. Den enda framgången de senaste trettio åren 
har varit brasilianska Arbetarpartiet (PT). Både i Sydkorea och Sydafrika finns viktiga, fackföreningsbaserade arbetarrörelser, men de saknar starka politiska organisationer: de sydafrikanska fackföreningarna överskuggas av karaktären på ANC:s styre, och de koreanska undergrävs av en småaktig fraktionalism, vilken i slutet av 2012 sköt väl utvecklade planer på ett förenat vänsterparti i sank.

Även om klasskampen i syd har varit framgångsrik i erövrandet av löneförhöjningar och något mindre fruktansvärda arbetsförhållanden verkar det inte sannolikt att den skulle utvecklas till ett mer systematiskt hot. Särskilt i Östasien uppnår industrikapitalismen nya högre konsumtionsnivåer i en takt som det för de europeiska ekonomierna, med sin långsammare utveckling, tog mycket längre tid att uppnå. Att kommunistpartier styr i Kina och Vietnam innebär förvisso att en antikapitalistisk vändning inte är otänkbar - och om försök gjordes skulle den vara genomförbar. Men för att det skulle hända krävs både ett stopp på tillväxten och en effektiv mobilisering av arbetare mot den enorma ojämlikhet som systemet har skapat, vilket hotar den kommunistiska kapitalismens sociala sammanhållning eller "harmoni”. Det är tänkbart, men ytterst osannolikt, åtminstone på tämligen lång sikt. Mer löftesrikt skulle scenariot vara om kampen på arbetsplatserna knöts till kampen i civilsamhället om bostäder, hälsa, utbildning och medborgerliga rättigheter.

\section{Tjänstemannamassor}

En färde potentiellt kritisk samhällskraft kan vara på väg att uppstå inom finanskapitalismens polariserande dialektik. Medelklasskikt, framför allt studenter, hade en ledande roll i rörelserna 20II - i Spanien, Grekland, det arabiska Mashriq', Chile liksom i de svagare Occupy-protesterna i Nordamerika och norra Europa - och i 2013 års protester i Brasilien och Turkiet. Dessa utbrott drev ungdomar från både medelklassen och folket ut på gatorna, i en del fall även deras föräldrar, till kamp mot korrupta, exkluderande, socialt polariserande kapitalistiska system. De lyckades inte begränsa kapitalets makt, även om rörelserna 2oII ledde

I. Mashriq är en arabisk term för de arabiska områdena i Mellanöstern. Övers. anm. 
till att två regeringar störtades. Men protesterna skulle kunna visa sig ha varit generalrepetitioner inför kommande dramer.

Det senaste decenniet har debatten om den nya medelklassen vuxit lavinartat. I och om Afrika, Asien och Latinamerika är diskussionen i huvudsak triumfatorisk - om Östeuropa ofta försiktigare - och förkunnar uppkomsten av en massmarknad av välbeställda konsumenter. Vare sig de har rätt eller fel är klassdiskurser alltid av social betydelse, så den globala framväxten av en diskussion om medelklassen är ett symptom på 20Io-talet värt att lägga märke till. För det mesta pekar de inte fram mot någon kritisk samhällelig dialektik, tvärtom applåderar de i allmänhet konsumismens seger. Arbetarklassen försvinner från de kinesiska och vietnamesiska kommunistpartiernas dokument, medan vi i det av Tyskland ledda Europa har sett självbilden som "lönearbetarsamhälle" från mitten av I900-talet ersättas av idealet om ett "entreprenörssamhälle". I allmänhet ser politiska kommentatorer medelklassen som en lovande grund för "sund" ekonomi och liberal demokrati, även om eftertänksamma ekonomer, särskilt i Brasilien, har betonat hur bräcklig "medelklassheten" är och den ständiga risk för fattigdom som många löper. I USA signalerar den rådande tonen tvärtom oro över medelklassens minskande ekonomiska status och sociala betydelse. Västeuropa har inte riktigt följt samma mönster: eftersom arbetarklassen här redan har en etablerad diskursiv närvaro har synen på medelklassen alltid brukat vara mer begränsad än i Amerika eller Asien - inklusive Kina efter Mao. Utanför Europa omfattar den nya föreställningen om medelklassen den väldiga andel av befolkningen som befinner sig i utrymmet mellan de mycket fattiga och de rika, med gränsen för fattigdom ofta satt till inkomster eller utgifter på 2, 4 eller Io dollar per dag, medan den övre gränsen bara utesluter de 5 eller Io rikaste procenten.

I motsats till industriarbetarklassen är den egendomliga grupp som kallas "medelklass" inte bärare av några specifika produktionsförhållanden, inte heller omfattar den någon speciell tendens i utvecklingen, frånsett oinskränkt konsumtion. Oavsett hur den definieras har medelklassen - eller ansenliga delar av den - trots det redan visat sin förmåga att vara en betydande politisk aktör, med allt större kraft i takt med industriproletariatets tillbakagång och desorganisering. De framväxande medel- 
klasserna i det globala syd förtjänar särskild uppmärksamhet, ty de kan vara centrala för att fälla avgörandet om de politiska alternativen.

Just på grund av medelklassens samhälleliga obestämbarhet kan dess styrka användas för olika, till och med motsatta, syften. Den mobiliserade medelklassen var en viktig kraft bakom Pinochets kupp i Chile, medan dess venezuelanska motsvarighet stödde ett misslyckat försök att störta Hugo Chávez 2002, och sex år senare störtade Bangkoks förmögna "gulskjortor" Thailands regering. Som I900-talets europeiska historia visar garanterar medelklassen inte i sig någon rörelse mot demokrati. Men den har också varit en källa till påtryckningar för demokratiska förändringar, och spelade - jämsides med industriarbetarna - en viktig roll i Taiwan och Sydkorea under 1980-talet, och i Östeuropa 1989. Den var en central kraft i Kairo och Tunis 2oII och stödde de folkliga gatuprotesterna i Grekland, Spanien, Chile och Brasilien 20II-20I3. Medelklassens politiska ombytlighet illustreras på ett färgstarkt sätt av de skarpa svängningarna i Egypten, från rop på demokrati till ett förhärligande av militären och dess ökande förtryck av oliktänkande, varigenom man i praktiken gick med på att återupprätta den gamla regimen minus Mubarak.

Kritiska ingripanden av medelklassens krafter kan också visa sig på det parlamentariska området. 2012 valde Mexico City, med en befolkning lika stor som ett medelstort europeiskt land, en vänsterinriktad borgmästare för fjärde valperioden i rad. Den segrande kandidaten, Miguel Ángel Mancera, fick nästan 64 procent av rösterna, vilket tyder på ett brett folkligt stöd. I Indien återstår att se hur det går för Aam Adami Party ("Den vanliga människans parti"). AAP:s och dess ledare Arvind Kejriwals uppseendeväckande stora framsteg var resultatet av en ny allians, som knöt medelklassens demonstranter mot korruption till en rad konkreta krav gällande tillgång till vatten och andra offentliga tjänster, som skulle kunna gynna bredare befolkningsskikt. Det nya partiet sopade banan med motståndarna i välmående delar av New Delhi, liksom i nio av de tolv valkretsarna för "lägre kaster", och övertog styret av huvudstaden 2013 - men lämnade ifrån sig makten bara 49 dagar senare, när deras ansträngningar att genom lagstiftning tygla korruptionen hindrades av uteblivet godkännande från den federala regeringen. I Indonesien vann en reformistisk kandidat, Jokowi, guvernörsvalet i Jakarta 2012 mot både 
det lokala etablissemanget och en illasinnad sekteristisk religiös kampanj - hans partner till att bli viceguvernör var en kinesisk kristen - med en plattform som gick ut på att bygga ut utbildning och sjukvård och gynna "entreprenörskap i städerna". Också här återstår att se hur starka och effektiva klassallianserna är - hur väl de klarar av att ge folkmassorna reella förbättringar. ${ }^{2}$

\section{Kritiska teman}

Ända sedan Blake fördömde dess "mörka djävulska fabriker" har kapitalismen - i synnerhet industrikapitalismen - varit föremål för kulturell kritik. Under lång tid kunde systemet enkelt navigera runt sådana klagomål, men "1968" gjorde den sortens sorglöshet omöjlig. De rörelser som detta år kommit att symbolisera hade inte någon särskild framgång $\mathrm{i}$ kampen mot själva kapitalismen, men de fick stor inverkan på samhällsförhållandena: de urholkade patriarkatet och misogynin, upphävde den institutionella rasismens legitimitet och naggade respekten för överheten i kanten - kort sagt gynnade de existentiell jämlikhet, framför allt i Europa och Amerika. Men dessa kulturella förändringar har till största delen införlivats i den utvecklade kapitalismen, i form av informalitet inom den högteknologiska industrin, ett ökat antal kvinnliga verkställande direktörer, allmän acceptans för homosexuellas rättigheter och samkönade äktenskap, den "borgerliga bohemen" som socialt fenomen, och så vidare.

De rörelser som har grundat sig på en kulturell kritik av det kapitalistiska samhället har antingen krävt en begränsning och reglering av den kapitalistiska utvecklingen eller föreslagit alternativa sätt att leva. De kommande årtiondena verkar bjuda på möjligheter för åtminstone fyra betydelsefulla sådana rörelser, omfattande både synsättet "begränsning" och "alternativ". Historiskt har de viktigaste argumenten för begränsningar riktat in sig på det hot som en ohämmad kapitalism utgör mot samhällets sammanhållning. Av nyare årgång är miljöfrågan och hotet

2. Än mer så sedan Jokowi erövrat presidentämbetet under 2014 (som president har han kunnat utnämna sin tidigare ställföreträdare till ny guvernör sedan parlamentet avskaffat de direkta valen till ämbetet). 
från industrialiseringens oavsiktliga, alltmer okontrollerbara, effekter på ekosystemet. Bland "alternativen" har socialismen för tillfället skjutits på framtiden, men det finns andra tydligt urskiljbara visioner, mer besläktade med kommunismen i dess ursprungliga marxistiska betydelse än I900-talets industrisocialism. För närvarande kan vi identifiera två sådana rörelser, eller åtminstone frön till dem, vilka båda utlovar en livskvalitet överlägsen den kapitalismen erbjuder. Den första, som bäst kommit till uttryck i Tyskland, utgår från erfarenheterna i de utvecklade länderna och betonar frågan om det som finns "bortom tillväxten". Den andra för fram ett geopolitiskt alternativ och hämtar sin kraft från det icke-kapitalistiska syd. Vi ska titta på var och en av dem i tur och ordning.

För det första är den sociala sammanhållningen mycket mindre avgörande för dagens härskande eliter än vad den var för deras motsvarigheter under tidigare sekel. Värnpliktsarméerna har till största delen ersatts av legoarméer, massmedierna har hjälpt till att göra inhemska val "hanterbara", den förhärskande ekonomiska sanningen säger att de internationella investerarnas känslor är viktigare för tillväxten än enhetlig utveckling. Om något anser eliterna i nord att sammanhållning innebär att invandrare ska pressas till assimilering i högre grad, i namn av "integration". Visserligen finns det officiellt en uppfattning inom EU att social sammanhållning är viktig, men i praktiken tolkas det huvudsakligen som sammanhållning i geografisk mening, med ekonomiskt stöd till utvecklingsprojekt i fattigare regioner. Under den nuvarande krisen har hårda åtstramningar genomdrivits mot befolkningarna i södra Europa, med föga offentligt intresse för den ökande sociala utslagningen. Uppenbarligen anses nationell sammanhållning inte längre avgörande för att uppnå imperialistisk makt - till skillnad från under I800- och I900talen, när revolutionen uppifrån i Meijiperiodens Japan och de mindre framgångsrika försöken i samma riktning av regimerna i Qings Kina och Osmanska riket såg sådan sammanhållning som grundvalen för modern geopolitisk styrka. Efter andra världskriget var en nationellt sammanhållen kapitalistisk utveckling målet både för de valda härskarna i Japan och för de militära härskarna i Taiwan och Sydkorea, vilket resulterade i industrisamhällen som i den kapitalistiska delen av världen bara kunde 
överträffas av de europeiska välfärdsstaterna i fråga om liten ekonomisk ojämlikhet. För Folkrepubliken Kinas ledare är social sammanhållning fortfarande ett avgörande kriterium för politiken. Den enorma ojämlikhet som spridits i Kina de senaste trettiofem åren - och som skiljer sig så mycket från Japans, Sydkoreas och Taiwans jämlika och snabba tillväxt - gör dess självbild som ett "harmoniskt samhälle" omöjlig att försvara i längden. Samma sak kan ske på andra håll i syd.

Icke desto mindre förblir social utslagning, ojämlikhet och upplösning en möjlig grund för kritik underifrån, något de senaste årens återkommande proteströrelser har visat. De faktiskt existerande kapitalistiska samhällena omfattas inte helt och hållet av Kapitalets logik: de innefattar också icke-kapitalistiska områden, inklusive offentliga tjänster och platser. För närvarande är kapitalismen inställd på att invadera alla det samhälleliga livets områden - och begränsa, om än (än så länge) inte nödvändigtvis avskaffa, allt offentligt. Intrången ger upphov till motstånd, till försvar för det offentliga och det icke-kommodifierade. På senare tid har denna typ av proteströrelse spridit sig över världen: mot privatiseringen av högre utbildning i Chile och andra delar av Latinamerika, mot kommersialiseringen av Istanbuls offentliga platser, och ett mer nedtonat men icke desto mindre utbrett motstånd mot marknadsanpassningen av skolor och sjukvårdstjänster i Sverige.

Kommodifieringen av sociala relationer och nyliberalernas undergrävande av varje tillstymmelse till allmänna intressen eller social ansvarskänsla har skapat oerhört goda möjligheter till korruption. Till och med i länder som tidigare styrts av en stark, om än nu hånad, etisk grundsyn på offentliga tjänster, som Sverige, har tvivelaktiga överenskommelser mellan det offentliga och det privata näringslivet blivit vanliga. I syd, där massiv korruption är allmänt utbredd i de flesta länder, inklusive i Kina och Vietnam, är antikorruptionskampanjer vanliga, men än så länge har de inte haft någon större effekt. Ibland blir de mer omfattande, som protesterna i Delhi, vilka inleddes 20II av Anna Hazare efter den flagranta plundringen som följde på Samväldesspelen 20IO, protester som sedan omvandlades till Aam Adami-partiet. Sannolikt kommer rörelser mot korruption och kommersiellt utnyttjande av det offentliga rummet och offentlig service att växa, både på grund av att provokationerna blir 
många fler och på grund av att medborgarna nu är kunnigare, mindre hänsynsfulla och lättare att mobilisera med hjälp av sociala medier. 2013 gav Turkiet ett föredömligt exempel på det. Men om dessa protester inte uppgår i bredare samhällspolitiska sammanhang kommer de - tillsammans med protesterna mot skuldsättning och vräkning - aldrig att röra sig utanför det kapitalistiska systemets gränser.

Miljöaktivisterna, med sin kritik av kapitalismen, organiserade sig som en social rörelse på 1980-talet, en rörelse som fortfarande har en hel del inflytande. Det finns anledning att hävda att den ekologiska utmaning som klimatförändringar, föroreningar av städerna, plundring av världshaven och uttömning av vattenresurserna utgör har gett nytt liv åt den marxistiska "stora dialektiken" mellan produktivkrafternas samhälleliga karaktär och de existerande egendomsförhållandenas krisskapande natur: en dialektik som upphävts på norra halvklotet genom avindustrialisering och finanskapitalismens seger. Vilken inverkan denna kritik kommer att få beror troligen på dess förmåga att utveckla former för kollektivt reglerat ansvar, samtidigt som den avstår från uppoffrande krav på nolltillväxt. En central fråga är den förödande föroreningen av kinesiska städer - inklusive, iögonfallande nog, Beijing - liksom städer på andra ställen i Asien. I Kina orsakar föroreningarna också skador på stora områden odlingsbar mark. Genom att kräva offentlig reglering skulle miljörörelsen kunna ansluta sig till kritikerna av den ohämmade finanskapitalistismen. Att vi har sett så få sådana allianser understryker den nordatlantiska vänsterns svaghet - för att inte tala om den ännu till stora delar oemotsagda kinesiska fixeringen vid att ekonomiskt "komma i kapp".

En kritik av konsumismen skulle kunna spänna över generationerna. "1968” var en ungdomsrörelse: "lita inte på någon över trettio". Under protesterna i Chile och runt Medelhavet 20II, och upproret i Brasilien 2013, förenade sig tvärtom föräldrarna ofta med de unga. Nyliberalismens förödande kris i Argentina i början av 2000-talet gav upphov till häftiga gatuprotester bland pensionärer som försvarade sina pensioner. Det skulle kunna uppstå en kritisk rörelse inom den åldrande befolkningen i Europa och Japan, särskilt bland äldre ur "1968"-generationen. I första hand skulle nog protesterna röra livskvalitet - lugn, trygghet, este- 
tiska frågor - i stället för ekonomisk tillväxt och ackumulering av kapital. Än så länge har vi dock inte sett mycket av detta. Sannolikt kommer en kritik av konsumismen inte få någon större draghjälp från områden utanför Europa och Japan, utom möjligen i Río de la Plata-regionen och bland ursprungsbefolkningar. Konsumism kommer sannolikt att förbli den främsta kulturella dynamiken.

Kritiken från det globala syd mot den nordatlantiska kapitalismen har tagit sig uttryck i rörelsen kring World Social Forum, och utvecklats vidare av den portugisiska forskaren Boaventura de Sousa Santos i hans bok Epistemologies of the South (2013). I och med den geopolitiska förskjutningen av den globala makten kommer den troligen att få ett ökat inflytande, men den kommer förmodligen också att möta ett djupt rotat motstånd, och detta inte bara från eliterna i nord. På södra halvklotet förför konsumismen stora nya befolkningsskikt, som tillber de köpcentrum som växer upp som svampar ur jorden. Den kritik som Santos och andra levererar borde skaka om nords kulturella arrogans. Deras problem är att de i huvudsak riktar sig till dem som förlorar på deras budskap: de "moderna" människorna i norr. Ändå torde den spegel från söder som World Social Forum har hållit upp för den atlantiska kapitalismen komma att införlivas i det norra halvklotets kritiska tänkande - precis som den borde.

För att summera: förkapitalistiska befolkningar, som kämpar för att bevara sina territorier och sitt levebröd; "överflödiga” massor, som har uteslutits från formella anställningar inom kapitalistisk produktion; exploaterade arbetare inom tillverkningsindustrin, spridda över "rostbälten" och "solbälten"; ny och gammal medelklass, alltmer tyngda av skuldåterbetalning till finansföretagen - dessa grupper utgör de möjliga sociala baserna för nutida kritik av den rådande kapitalistiska samhällsordningen. För att de ska kunna göra framsteg krävs nästan säkert allianser dem emellan, och därmed samordning av deras intressen. En avgörande faktor kommer att bli på vilken sida, eller vilka sidor, de nya medelklasserna i Afrika, Asien och Latinamerika ställer sig.

Under I80o-talet gick den framväxande medelklassen i spetsen för den kapitalistiska utvecklingen i Europa och Amerika, men så ser det inte längre ut. Finanskapitalet och de multinationella företagen har 
för länge sedan övertagit den rollen. I stället måste medelklassen välja sida i samhällen som är starkt polariserade: antingen står de med oligarkerna mot de fattiga eller med folket mot oligarkerna. Varje kritik av 2000-talets kapitalism som ska kunna vara livskraftig kommer att behöva få med sig en stor del av medelklassen. Den behöver ta sig an några av klassens mest centrala frågor och försöka formulera dem i en kritisk och jämlikhetssträvande riktning. Det kräver respekt för klassiska medelklassvärderingar som vikten av hårt arbete, självständighet, förnuft och rättvisa. Det måste också klargöras att dessa intressen är förenliga med folkliga krav på deltagande och jämlikhet, och oförenliga med de hänsynslösa finanseliternas, kompiskapitalisternas och de korrupta eller auktoritära regimernas praktik. Medelklassen - i synnerhet dess avlönade och anställda delar - kan också vara öppna för en kulturell kritik av kapitalismen, särskilt i frågor som gäller miljö och livskvalitet. Eftersom medelklasspolitiken är ombytlig kräver dock varje vändning i progressiv riktning att starka folkliga krafter mobiliseras inom de första två samhällsströmningar som nämndes ovan: invaderade eller utstötta förkapitalistiska folkgrupper, och arbetare som försvarar sig själva inom produktionssfären. 


\section{Moderna klassiker}

\section{Marie Jahoda}

\section{Paul F. Lazarsfeld, Hans Zeisel De arbetslösa i Marienthal}

\section{Arkiv förlag}

De arbetslösa $i$ Marienthal (Die Arbeitslosen von Marienthal) från I933 av Marie Jahoda, Paul F. Lazarsfeld och Hans Zeisel är ett av samhällsvetenskapens mest legendariska arbeten. $\mathrm{Nu}$ finns den för första gången på svenska. Marienthalstudien lade grunden till mycket av dagens arbetslöshetsforskning och var banbrytande i sitt sätt att kombinera kvalitativa och kvantitativa data på ett sätt som fortfarande inspirerar. En inledning av den österrikiske sociologen Christian Fleck och ett efterord av den svenske sociologen Paavo Bergman presenterar verket och dess betydelse för samhällsvetenskapen.

Översättning Svenja Hums Arkiv förlag 20I4, I90 sidor 


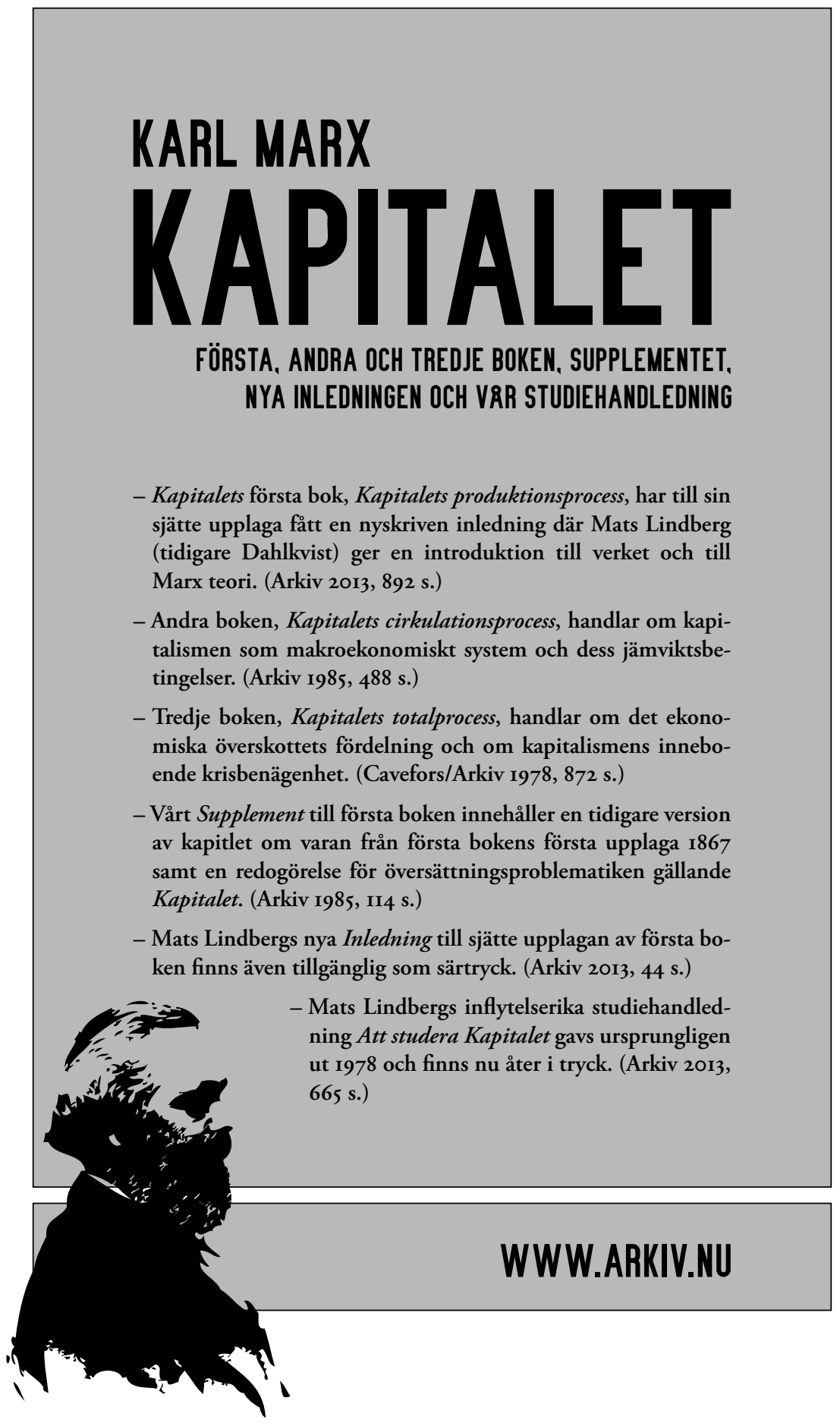

